\title{
Inertial Confinement Fusion (ICF) Review
}

\author{
David Hammer, Chair \\ Freeman Dyson \\ Norval Fortson \\ Bob Novick \\ Wolfgang Panofsky \\ Marshall Rosenbluth \\ Sam Treiman \\ Herbent York
}

March 1996

JSR-96-300

Approved for public release; distribution unlimited

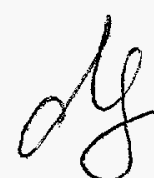

ESTRIBUTION OF MHS DOCUMENT IS UNLIMTTED

JASON

The MITRE Corporation 1820 Dolley Madison Blvd. McLean, Virginia 22102-3481

(703) 883-6997
MASTER 


\section{DISCLAIMER}

This report was prepared as an account of work sponsored by an agency of the United States Government. Neither the United States Government nor any agency thereof, nor any of their employees, make any warranty, express or implied, or assumes any legal liability or responsibility for the accuracy, completeness, or usefulness of any information, apparatus, product, or process disclosed, or represents that its use would not infringe privately owned rights. Reference herein to any specific commercial product, process, or service by trade name, trademark, manufacturer, or otherwise does not necessarily constitute or imply its endorsement, recommendation, or favoring by the United States Government or any agency thereof. The views and opinions of authors expressed herein do not necessarily state or reflect those of the United States Government or any agency thereof. 


\section{DISCLAIMER}

Portions of this document may be illegible electronic image products. Images are produced from the best available original document. 


\begin{tabular}{|c|c|c|c|}
\hline \multicolumn{3}{|c|}{ REPORT DOCUMENTATION PAGE } & $\begin{array}{l}\text { Form Approved } \\
\text { OMB No. } 07040188\end{array}$ \\
\hline \multicolumn{4}{|c|}{ 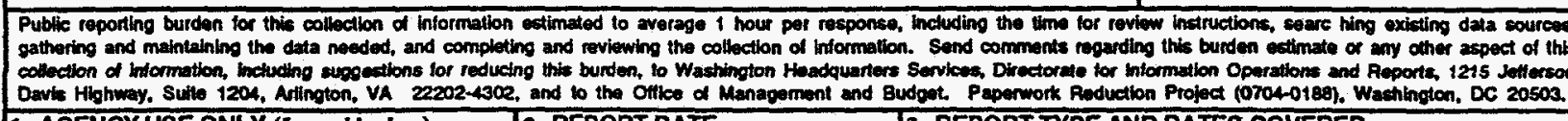 } \\
\hline 1. AGENCY USE ONLY (Leave blank ） & \begin{tabular}{l|l} 
2. REPORT DATE \\
March 11,1
\end{tabular} & 3. REPORT TYPEAN & DODATES COVERED \\
\hline \multicolumn{3}{|l|}{ 4. TITLE AND SUBTITLE } & 5. FUNDING NUMBERS \\
\hline \multicolumn{3}{|c|}{ Inertial Confinement Fusion (ICF) Review } & \multirow{3}{*}{$07-958534-04$} \\
\hline \multirow{2}{*}{\multicolumn{3}{|c|}{$\begin{array}{l}\text { 6. AUTHOR(S) } \\
\text { D. Hammer, F. Dyson, N. Fortson, B. Novick, W. Panofsky, M. Rosenbluth, } \\
\text { S. Treiman, H. York }\end{array}$}} & \\
\hline & & & \\
\hline \multicolumn{3}{|c|}{ 7. PERFORMING OAGANIZATION NAME(S) AND ADDRESS(ES) } & 8. PERFOPAIING ORGANIZATION \\
\hline \multicolumn{3}{|c|}{$\begin{array}{l}\text { The MITE Corporation } \\
\text { JASON Program Office } \\
1820 \text { Dolley Madison Blvd } \\
\text { McLean Virginia } 22102\end{array}$} & JSR-96-300 \\
\hline \multicolumn{3}{|c|}{ 9. SPONSORINGMONITORING AGENCY NAME(S) AND ADDRESS(ES) } & $\begin{array}{l}\text { 10. SPONSORINGMONITORING } \\
\text { AGENCY REPORT NUMBER }\end{array}$ \\
\hline \multicolumn{3}{|c|}{$\begin{array}{l}\text { US Deparment of Energy } \\
\text { ER/30 OER } \\
\text { Washington, DC 20585-1290 }\end{array}$} & JSR-96-300 \\
\hline \multicolumn{4}{|l|}{ 11. SUPPLEMENTARY NOTES } \\
\hline \multicolumn{3}{|c|}{ Approved for public release; distribution unlimited. } & $\begin{array}{l}\text { 12b. DISTRIBUTION CODE } \\
\text { Distribution Statement A }\end{array}$ \\
\hline \multicolumn{4}{|c|}{ 13. ABSTRACT (Maximum 200 words) } \\
\hline \multicolumn{4}{|c|}{$\begin{array}{l}\text { During its } 1996 \text { Winter Study JASON reviewed the DOE Inertial Confinement Fusion (ICF) } \\
\text { Program. This included the National Ignition Facility (NIF) and proposed studies. The result } \\
\text { of the review was to comment on the role of the ICF program in support of the DOE Science } \\
\text { Based Stockpile Stewardship program. }\end{array}$} \\
\hline \multirow{2}{*}{\multicolumn{3}{|c|}{ 14. SUBJECT TERMS }} & 75. NUMBER OF PAGES \\
\hline & & & 16. PRICE COUE \\
\hline $\begin{array}{l}\text { 7. SECURITY CLASSIFICATION } \\
\text { OF REPOAT }\end{array}$ & $\begin{array}{l}\text { 18. SECUAITY CLASSIFICATION } \\
\text { OF THIS PAGE }\end{array}$ & $\begin{array}{l}\text { 19. SECURITY CLASSIFICATION } \\
\text { OF ABSTRACT }\end{array}$ & 20. LIMITATION OF ABSTAACT \\
\hline Unclassified & Unclassified & Unclassified & SAR \\
\hline
\end{tabular}




\section{Contents}

1 INTRODUCTION AND SUMMARY 1

2 THE ICF - SBSS CONNECTION 7

3 FINDINGS AND RECOMMENDATIONS 11

A APPENDIX - TASK STATEMENT 19 


\section{INTRODUCTION AND SUMMARY}

In 1994, JASON carried out a summer study on the Department of Energy - Defense Program's (DOE/DP's) Science Based Stockpile Stewardship (SBSS) program. As a part of that study, the proposed National Ignition Facility (NIF) of the Inertial Confinement Fusion (ICF) program was reviewed and determined to be "...the most scientifically valuable of the programs proposed for SBSS, particularly in regard to ICF research and a 'proof-of-principle' for ignition, but also more generally for fundamental science." (JSR-94-345, p. 5.) For the winter study of 1996, JASON was given the following task by DOE/DP:

To delineate the technical activities that best support stewardship needs, please examine the existing ICF Program and update your previous review of NIF by considering new studies of possible experiments. Specifically, identify how each program element will contribute directly to important stewardship issues or indirectly to them by increasing confidence in the success of NIF.

(See Appendix A for the full text of the task statement.)

In support of this request, on January 17,1996 , the ICF program managers of each of the major laboratories participating in the ICF program were called upon to provide a summary to members of JASON on present and planned ICF program activities, emphasizing how those activities contribute to the stockpile stewardship program. ${ }^{1}$ In addition, an update of

\footnotetext{
${ }^{1}$ The exception was General Atomics, which was not asked to make a presentation because of their well-defined role in the development of cryogenic fuel capsules.
} 

contribute to achieving the long-term SBSS objectives in the future. How to assure a reasonable balance in funding between current and future stockpile stewardship needs, especially with regards to building new facilities, was a major concern of our three advisors from the weapons designer community, a concern which we share.

In the context of the situation described in the last paragraph, we are convinced that the present ICF program does make an important contribution to SBSS, and that the NIF will substantially increase this contribution. Therefore, we believe the ICF program, including the NIF, should be supported as part of the present Stockpile Stewardship and Management Program. In reaching this conclusion, we included in our thinking the potential scientific and technology development value of the NIF outside as well as inside the weapons program, the quality of the research and development being carried out in the ICF program now, and the long-term payoff to our country of ICF's and NIF's contributing both to a safe, secure and reliable stockpile through SBSS, and also to a useful energy resource through inertial confinement fusion. ${ }^{3}$ With regard to SBSS specifically, we find that the ICF program now, and the NIF eventually, can contribute a great deal to the weapons physics data base, to the validation of weapon design and evaluation codes, and other issues directly related to the weapon program. This will be true especially if the NIF accomplishes its scientifically and technologically challenging goal of achieving ignition. The synergy between ICF, as a validation tool, and the new, powerful codes to be expected from the Accelerated Scientific Computing Initiative (ASCI), will give increased confidence in assessing the effects of design or aging defects.

\footnotetext{
${ }^{3}$ Although the success of the NIF will be a crucial step toward developing ICF as an energy resource, the specific laser technology in the NIF is unlikely to be useful in an economical energy-producing facility.
} 
In the long term the ICF program will also play a major role in SBSS by continuing to attract the top quality young scientists who will be needed to ensure that the long term goals of SBSS are achieved. This latter value is becoming more evident as scientists in the weapons laboratories in particular are now moving back and forth more and more between the ICF program and the other weapons program activities in the laboratories. For example, active encouragement of such movement of people at LANL has recently resulted in contributions by weapons designers to new and innovative ignition target designs, to utilization of tritium and beryllium expertise at LANL in pursuit of both ICF and stewardship goals, and to the use of ICF measurement methods in performing experiments to obtain weapons physics data. This exchange of people between different parts of the SBSS program is an excellent way to guarantee that clever, potentially beneficial ideas and developments in the ICF program will be utilized to best advantage for stockpile stewardship. Clearly, LANL, LLNL, and SNLA are the key institutions at which people must carry knowledge, skills and ideas between the various important stewardship activities.

It is also noteworthy that the present and near-term direct contributions of the ICF program to SBSS are growing as weapons scientists find that ICF facilities are capable of providing relevant data. Also, computer codes developed in the ICF program are of value even now to weapon evaluation and other important near-term activities. We will provide an example of this in the next section. As a general observation, we believe that the current program strikes a reasonable balance between these studies with more immediate applications and activities that contribute to the more long term goals of ICF and SBSS. 
In summary form, our conclusions and recommendations are as follows, with support provided in Section 3:

1. We believe that the ICF program is an important element in the SBSS program now, and we reaffirm our previously-stated (JSR-94-345) support for proceeding to the next step of achieving ignition with the NIF because of the NIF's expected value to SBSS as well as its collateral scientific and energy interest.

2. The present breadth of the program is an important part of its strength and should not be reduced; and

3. Although funding limitations in future years will become increasingly severe, it will be important to continue NOVA operations at least until NIF construction is well underway and the Omega Upgrade facility has proven itself a valuable resource for obtaining weapon-physics data. 



\section{THE ICF - SBSS CONNECTION}

The ICF program contributes to SBSS in both direct and indirect ways. The category of direct contributions includes such activities as the use of ICF facilities for obtaining weapons physics data, for carrying out experiments that permit important computer codes to be validated, and for carrying out experiments and/or computer calculations that give insight into the solution to a specific problem identified by the stockpile maintenance program. Indirect contributions include research and development that contribute to a successful NIF (and eventually to a high gain facility), developing improved capabilities for existing facilities so as to improve their value to the weapons community, carrying out research, such as on hydrodynamic instabilities, that can impact understanding of both ICF capsules for NIF and weapon physics issues, and providing the kind of exciting, innovative science that will continue to help attract outstanding scientists to the nuclear weapons laboratories. It is our belief that the ICF program as presently constituted, including the prospect that in a few years there will be a NIF, is making important contribution to SBSS both directly and indirectly.

Although it is easy to delineate specific examples of direct contributions, and one is described in detail below, we believe that the "future value" of the ICF program elements, and especially the NIF, is where the major potential benefits lie. The most urgent (short-term) needs of laboratory scientists for stockpile stewardship are mostly at a level far more practical than can be addressed by ICF except in a few specific cases. (Two examples we heard about were pulsed power applications to a few of SNLA's remanufacturing problems, and LANL and LLNL scientists' carrying out NOVA experiments 
with imperfect capsules to benchmark codes used to calculate the effects of specific aging problems found in stockpile weapons.) Therefore, the future benefits of ICF program elements, and the NIF in particular, must be weighed more heavily than they might otherwise be in considering the merits of the program. In fact, they represent "seed corn" for future capability when today's practical problems are solved. For example, the program at the University of Rochester (UR) has a specific goal in ICF, namely the development of direct drive as a possible option for achieving ignition. The success of the UR program could, therefore, impact the success of the NIF, and UR is uniquely a place where the continuing involvement of a cadre of talented, appropriately trained young scientists can be assured for future involvement in SBSS.

A major element of each program presentation was the present and nearfuture direct contribution of that program to SBSS. We were, in fact, very favorably impressed by the range of weapons physics data that is actually being collected using the NOVA laser facility. In particular, weapons program scientists at LLNL and LANL consider the facility sufficiently useful that they are utilizing, and paying for, nearly $20 \%$ of the NOVA Facility pulses to obtain data relevant to weapons physics issues. We also applaud the much closer working relationships and more direct communication channels that have developed in the last couple of years among ICF and other weapons program scientists. The explicit goal is to assure that the needs of weapons designers and evaluators that can be addressed by present ICF program capabilities (facilities, codes, diagnostics; etc.) are being addressed. Direct application of ICF program capability to weapons physics is exemplified by the following. 
A critical parameter in nuclear weapon design and weapon-test-analysis calculations is the opacity; it is needed for many materials as a function of temperature and density over a wide range of both of those variables. Recent opacity measurements on NOVA utilized clever techniques to produce an exacting test of an important current numerical model used to calculate opacities. The method involves placing a sample of the material under study in a hohlraum and heating it with the laser beams to a temperature of a few tens of electron volts. An x-ray transmission spectrum in the few $\mathrm{keV}$ energy range was obtained for the sample material using an $\mathrm{x}$-ray point source created by a separately. focused NOVA beam. The method permits a simultaneous measurement of the material temperature because both the strength and shape of the transmission spectrum vary rapidly with temperature. The excellent agreement between the experiment and the predictions of the numerical model provides an important benchmark for the code, and also provides guidance on some outstanding weapon physics issues. We must note, however, that using the code to predict opacities in nuclear weapons still involves a substantial extrapolation. In the absence of underground nuclear tests, only when the NIF is available and ignition achieved will it be possible to benchmark codes under conditions close to those in actual weapons. Therefore, the NIF is likely to be of great value to developing the capability for fully interpreting and achieving a science-based understanding of our underground test data-base.

We close this section with an excellent example of a technical achievement of the ICF program which provides important indirect benefit to stockpile stewardship by attracting bright young experimentalists and theorists to the laboratories to work on DOE/DP programs. Experiments at LLNL have now developed "soft $x$-ray" lasers with photon energies in the $50-80$ 
$\mathrm{eV}$ range to the point that they can make an interferometer capable of accurately diagnosing the density in very high density plasmas. The NOVA laser generates a dense plasma which is to be diagnosed by being directed onto one target, and also hits a second target which is used to produce the $\mathrm{x}$-ray laser beam. The beam is directed through a Mach-Zehnder interferometer containing the sample plasma in one arm, and the recombined beam is imaged onto a two dimensional CCD detector array. The availability of this new capability will probably lead to its application when a hohlraum diagnostic in weapons physics experiments when it becomes more routine. In the meantime, the possibility of obtaining even higher photon energy $x$-ray laser beams for SBSS and other will be a considerable magnet for the SBSS program to attract bright young scientists. 


\section{FINDINGS AND RECOMMENDATIONS}

Within the long-term tasks and objectives of the stockpile stewardship program, the ICF program and its next major objective, achieving ignition using the NIF, are key elements. The NIF in particular still appears to us to be "... the most scientifically valuable of the programs proposed for SBSS..." It will have both direct and indirect value to SBSS and it is a necessary stepping stone to a high yield facility (HYF), still the ultimate goal of the ICF program. The range of potential uses of the NIF by the weapons physics community (e.g.- equation-of-state and opacity measurements at high energy density, validating codes, etc.) is growing as that community of scientists is made aware of its anticipated capabilities (both without and with ignition of a fusion fuel capsule). We expect the growth of applications will continue as more and more weapons scientists come to terms with the fact that they will have to do without underground nuclear tests, including hydronuclear, indefinitely. The range of other scientific opportunities offered by the facility is also growing as DOE and laboratory scientists are making a concerted effort to inform the academic community of the possibilities for novel experimental situations offered by the NIF. Therefore, on balance, we find the case for supporting NIF together with the base ICF program as a component of SBSS as compelling as it was in the summer of 1994 . We are aided in reaching this conclusion by the considerable progress made by the ICF program in the last 18 months toward increasing confidence that ignition will be achieved in NIF experiments.

A new point brought up by our weapon laboratory advisors is that serious consideration should be given to the benefits of having a second target 
chamber included as an option in the NIF design. The second chamber would be primarily for classified experiments, but it could increase the potential value of the facility to the whole user community substantially by permitting the first target chamber to be kept available for unclassified uses at all times. The "diplomatic" value of not having to exclude uncleared users from the NIF target area when classified pieces of hardware are being installed is worth considering also.

At this point, it is appropriate to bring up the tension between the openness of the ICF program and the need for this program, eventually including the NIF, to contribute to the long term goals of SBSS. Openness is needed to inspire confidence in the worldwide community that SBSS is not hiding the development of a new generation of nuclear weapons, enabled somehow by the connection between ICF and the physics of secondaries. At the same time, the ICF program must be structured to meet the specific objective of assuring that the United States maintains a safe and reliable nuclear weapons stockpile indefinitely, including maintaining a cadre of topnotch physicists and engineers capable of designing nuclear weapons should the national interest require it some day in the future. Openness will be enhanced by further declassification of ICF science and technology and by providing access for uncleared American as well as foreign scientists to carry out experiments on ICF facilities, including the NIF. That access should be managed through an independent advisory committee, the membership of which is qualified to judge the scientific merits of submitted proposals as well as the value of proposals to SBSS. (Those committee members should also be alert to activities by foreign users that might serve clandestine nuclear weapon development activities.) Although DOE/DP is in the midst of developing a facility use plan for the NIF, we believe that the difficulty 
of managing the tension between openness and credibility on the one hand, and assuring the utility of the ICF program to SBSS, on the other hand, is a serious issue and will require considerable attention by DOE/DP.

In an era of budgetary stringency, it is necessary to seriously: consider the value of each element of the ICF program. Since achieving ignition at the NIF is the highest priority goal of the program,it is clear that the NIF design effort being undertaken as a multilab (LLNL, LANL, SNLA and University of Rochester) collaboration, and the intense effort by LANL and LLNL to address ignition issues through experiments on NOVA and modeling of targets, are absolutely essential program elements. (We note that collaboration on NOVA experiments, and intense peer review of each other's work on target modeling and analysis of experiments, has made the efforts of LANL and LLNL scientists all the more effective in recent years.) In the following paragraphs, we discuss the value and importance of the program elements other than those mentioned above. Overall, we conclude that the other elements of the program are of high quality and do contribute significantly to the prospects for ICF success. Furthermore, it is clearly desirable to maintain a broad intellectual constituency for ICF.

By the end of 1996, Omega Upgrade at the University of Rochester (UR) should be the highest power laser with the best optical quality in the highest power range. As such, it clearly will become the test bed for many NIF-related experiments, especially with regard to direct drive, as well as for investigating pulse-shaping and bandwidth requirements. It is envisioned that weapons physics scientists will increasingly rely on Omega Upgrade until the NIF is available. In particular, it is possible that for budgetary reasons, NOVA will not be able to operate continuously until the NIF is operational, 
in which case Omega Upgrade will be the prime facility of the ICF program for a period of years. The educational and outreach function of the National Laser Users Facility at UR are also of great value to the ICF program. In particular, we note that scientists trained at UR are playing important roles in the LLNL laser technology development program, in NOVA experiments and on the NIF design team.

The Naval Research Laboratory (NRL) program provides valuable input to the ICF program and SBSS in several areas. Of immediate importance to NIF design are Nike's near term capability for flat target studies of imprinting and bandwidth effects of especial interest to the direct drive option. The results and implications of these studies should be considered, and the direction of the program re-evaluated, in 18 months to 2 years. In the very long term, $\mathrm{KrF}$ lasers may be a good candidate for a direct drive high yield facility (HYF) or for the ICF-energy application. However, a long development path, which we do not advocate starting at this time, will be required. NRL has also provided very critical innovations (such as ISI - induced spatial incoherence - for laser beam smoothing) and has great capabilities in code development and atomic physics. We note, however, that NRL's role in the ICF program would be substantially more valuable if its team of scientists were collaborating more effectively with scientists in other ICF laboratories than has been the case up to now. In particular, inputs from NRL and other laboratories on specific topics should be evaluated collectively (as is now done effectively among other ICF laboratories) in order to attempt to reach a scientific consensus.

The SNLA program now contributes in two ways to the ICF and SBSS programs other than direct support for the NIF, namely through its work on 
ion beams for the HYF facility, and through the availability of ICF-developed facilities for radiography and for production of intensely radiating z-pinch plasmas which are used for both nuclear weapon effects testing and large scale, medium temperature hohlraum experiments. The z-pinch experiments are expected to provide important data for the NIF as well as for weapon science. Code development, including 3D hydrodynamics and particle-in-cell codes, plays an important role in all aspects of SNLA's program as well. The light ion beam program has suffered from parasitic losses in the ion diode and high beam divergence in recent years. PBFA-X, a new, more accessible configuration of the PBFA-II accelerator, offers the opportunity to eliminate the contamination thought to be responsible for these problems. Whether or not there is continuing promise for light ions as an HYF driver should become clear within the next two years. The SNLA direct support for NIF takes the form of responsibility for power conditioning systems, target chamber design, development of diagnostic packages and design of an internal pulse-shaping target for NIF.

A general remark is in order concerning the fact that all of the ICF programs discussed in this report are now engaged in major ICF target code development efforts. We believe that this is appropriate under the ASCI program, especially given the specialized needs of some of the groups (e.g.- UR's must be fully unclassified). We feel, however, that some further degree of coordination would be beneficial, such as developing bench marking problems. An overall strategy should be set up to make sure the critical issues such as hydrodynamic instabilities, mix and burn in $3 \mathrm{D}$, etc., are being effectively covered in the most effective way. We believe that complementarity should be stressed and excessive duplication, not now a problem, should be avoided. 
Finally, we take up the question of how long it is appropriate to continue to operate the NOVA Facility, given that the Omega Upgrade is now operational. There are several reasons to keep NOVA going as long as possible. Firstly, no matter how inviting UR makes the Omega facility to the weapon scientist community, its members are more likely to make use of a big laser facility if it is within the familiar surroundings of a weapon laboratory. Secondly, as the focus of SBSS shifts from short term problems to longer term tasks, there may be a need for more time for weapon physics experiments on high energy lasers than can be made available on Omega Upgrade. Finally, it would be beneficial if LLNL can keep NOVA going until the NOVA facility scientists and technical staff have to begin preparing to bring up and operate the laser system at the NIF. Unfortunately, budgetary restrictions rather than programmatic needs are likely to determine when NOVA is shut down. We recommend that NOVA operations should continue at least until both of the following are true: NIF construction is well underway and the Omega Upgrade Facility has proven itself a valuable resource for obtaining weapon-physics data. 
A APPENDIX - TASK STATEMENT 


\title{
memorandum
}

\author{
Date: January 11, 1996 \\ Subject: JASON' \& Review \\ To: Distribution
}

This is the task statement for the JASON's review of ICF/Stewardship. Each Laboratory (except General Atomics) should be prepared to present their ICF program elements and their relationship to stewardship. Each presentor will have approximately one hour on January 17 . You should also plan stay until noon on January 18 to respond to turther questions from the JASONS.

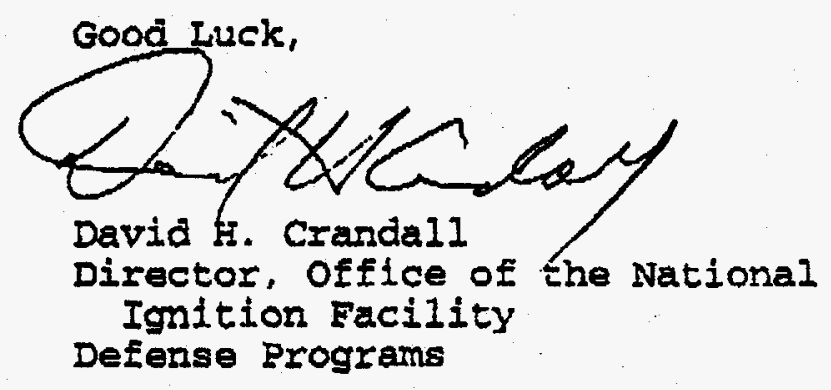

Distribution:

D. Baldwin

S. Bodiner

M. Cray

D. Hammer

B. Hezdersón

J. Ki ikeriny

S. Koonin

R. MeCrory

J. Quintenz

M. Rosenbluth

M. Sluyter

c: M. Cambe::.

D. $\operatorname{cec} k$

R. Fisher

Col. Harria

$\checkmark$. Immele

J. Landers

J. Eindl

J. Mercer-Smith

J. Pajsier

D. Patteraon

if. Powell 
Task statement

Jason Review of ICE for Stewardship

January $17-18,1996$

The Inertial Confinement Fusion (ICF) Program, and therefore, the National Ignition Facility (NIF) are justified for their value in sclence-basec stewardship of the nuclear weapons stockpile. The principle goal of the NIF is established as fusion ignition. Fusion and high energy aensity experiments at the NIF would be used to evaluate the effect of changes in weapons due to aging or remanufacture, validate important aspects of advanced computer models, and maintain core scientific capabilities in important areas of high energy denstty weapon physics. The JASON has previously stated that "the NIF is without question the most scientifically valuable of the programs proposed for science-based stockpice stewardship."

To delineate the technical activities that best support stewardship needs, please examine the existing ICF program and update your previous review of NIF by considering new studies of possible user experiments. Specifically, identify how each program element will contribute directly to the important stewardship issues or indirectly to them by increasing confidence in the success of NIF.

\section{Additional Background:}

The goals ana strategies for stewardship are contained in "The Stockpile Stewardship and Management Program" published by the Department of Energy in May 1995. The previous report. by the JASON, "Science Bzsed Stockpile Stewardship," JSR-94-345. discusses the overall value of the NIF and ICF in stewaraship. The present request is for an extension of that stuay to incluie consideration of additional types of experiments that can be done on NIF and to specifically delineate internal, techrical ICF activities, and identify how each supports the storkpile stewardship Program. Your report will assist us in program management and in responding to a recent reguest from Senator Domenici's office.

For maximum value to ls, a brief report by March 1, 1996 will be most useful. 
Pete V. DOMENICI NEW MEXICO

\section{United States Smate}

WASHINGTON, DE 20510-9101

January 10, 1995

The Eonorable Razel R. O'Leary

Secretary

Department of Energy

1000 Independence Avenue, sw

Washington, DC 20585

Dear Secretary O'Leary:

The Department of Energy's Inertial Canfinement Fusion (ICF) progran is Eunded by the Atomic Energy Defense Activitles account because the knowledge of besle atomic phyeics abd hydrodymanic: achieved through the ICF program is necessery to nuclear weapone stewardship.

In considering the Energy and water Appropriations Act for fiscal year 1996, the Congrese endoraed and provided initial funding within the ICF account for the National Ignition pac1i1ty (NIF) to pursue this knowledge.

I appreciate that thero are numerous other potential benefita that could be derived from the construction and operation of the NIF. However, the funding that has been provided is juetleled by NIF'B relevance to stockpile stewardship.

Becaupe of NIF's importance and cogt, it would ald future congredejonal coneideration of the ICF program if a number of issuee relating to ICF and the MIF wero addresed. Firat, the eet of stewardahlp requirement. NIP is intended to Eulfill needs to be crunclated. Second, NIF's design and operation: priorities, and prlorities for other parts of the ICF program that directly oupport the NIF, need to be established. In addition, the relationship between the NIF and the rest of the ICZ program needs to be clearly defined.

I hope you will consider conveniag a panel with an expertise in sefence-based tockplle stewardah1p to review these isauen. Because of its previous experience with acience based atockplie stowardship and ability to conduct a reviaw in a relatively ahort pariod of time, the Jasons might be ldeal for such a takk.

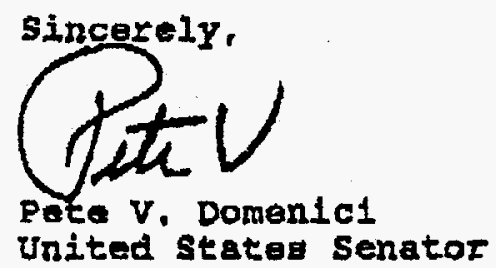


Director of Space and SDI Programs SAF/AQSC 1060 Air Force Pentagon

Washington, DC 20330-1060

CMDR \& Program Executive Officer U S Army/CSSD-ZA Strategic Defense Command PO Box 15280

Arlington, VA 22215-0150

A R P A Library

3701 North Fairfax Drive

Arlington, VA 22209-2308

Dr Arthur E Bisson

Director

Technology Directorate

Office of Naval Research

Room 407

800 N. Quincy Street

Arlington, VA 20350-1000

Dr Albert Brandenstein

Chief Scientist

Office of Nat'1 Drug Control Policy

Executive Office of the President

Washington, DC 20500

Mr. Edward Brown

Assistant Director

ARPA/SISTO

3701 North Fairfax Drive

Arlington, VA 22203

Dr H Lee Buchanan, II I

Director

ARPA/DSO

3701 North Fairfax Drive

Arlington, VA 22203-1714
Dr Ashton B Carter

Nuclear Security \& Counter Proliferation Office of the Secretary of Defense

The Pentagon, Room 4E821

Washington, DC 20301-2600

Dr Collier

Chief Scientist

U S Army Strategic Defense Command PO Box 15280

Arlington, VA 22215-0280

Dr Ken Cress

Office of Research and Development

Washington, DC 20505

DTIC [2]

Cameron Station

Alexandria, VA 22314

Mr John Darrah

Senior Scientist and Technical Advisor HQAF SPACOM/CN

Peterson AFB, CO 80914-5001

Dr Victor Demarines, Jr.

President and Chief Exec Officer

The MITRE Corporation

A210

202 Burlington Road

Bedford, MA 01730-1420

Mr Dan Flynn [5]

OSWR

Washington, DC 20505

Dr Paris Genalis

Deputy Director

OUSD(A\&T)/S\&TS/NW

The Pentagon, Room 3D1048

Washington, DC 20301 
Dr Lawrence K. Gershwin

NIC/NIO/S\&T

7E47, OHB

Washington, DC 20505

Mr. Thomas $\mathrm{H}$ Handel

Office of Naval Intelligence

The Pentagon, Room 5D660

Washington, DC 20350-2000

Dr Robert G Henderson

Director

JASON Program Office

The MITRE Corporation

7525 Colshire Drive

Mailstop Z561

McLean, VA 22102

Dr William E Howard I I I [2]

Director of Advanced Concepts \&

Systems Design

The Pentagon Room 3E480

Washington, DC 20301-0103

Dr Gerald J Iafrate

U S Army Research Office

PO Box 12211

4330 South Miami Boulevard

Research Triangle NC 27709-2211

J A S O N Library [5]

The MTTRE Corporation

Mail Stop W002

7525 Colshire Drive

McLean, VA 22102

Dr Anita Jones

Department of Defense

DOD, DDR\&E

The Pentagon, Room 3E1014

Washington, DC 20301
Mr. O' Dean P. Judd

Los Alamos National Laboratory Mailstop F650

Los Alamos, NM 87545

Dr Bobby $R$ Junker

Office of Naval Research

Code 111

800 North Quincy Street

Arlington, VA 22217

Lt Gen, Howard W. Leaf, ( Retired)

Director, Test and Evaluation

HQ USAF/TE

1650 Air Force Pentagon

Washington, DC 20330-1650

Mr. Larry Lynn

Director

ARPA/DIRO

3701 North Fairfax Drive

Arlington, VA 22203-1714

Dr. John Lyons

Director of Corporate Laboratory

US Army Laboratory Command

2800 Powder Mill Road

Adelphi, MD 20783-1145

Col Ed Mahen

ARPA/DIRO

3701 North Fairfax Drive

Arlington, VA 22203-1714

Dr. Arthur Manfredi

OSWR

Washington, DC 20505 
Mr James J Mattice

Deputy Asst Secretary

(Research \& Engineering)

$\mathrm{SAF} / \mathrm{AQ}$

Pentagon, Room 4D-977

Washington, DC 20330-1000

Dr George Mayer

Office of Director of Defense

Reserach and Engineering

Pentagon, Room 3D375

Washington, DC 20301-3030

Dr Bill Murphy

ORD

Washington, DC 20505

Mr Ronald Murphy

ARPA/ASTO

3701 North Fairfax Drive

Arlington, VA 22203-1714

Dr Julian C Nall

Institute for Defense Analyses 1801 North Beauregard Street Alexandria, VA 22311

Dr Ari Patrinos

Director

Environmental Sciences Division

ER74/GTN

US Department of Energy

Washington, DC 20585

Dr Bruce Pierce

USD(A)D S

The Pentagon, Room 3D136

Washington, DC 20301-3090

Dr William H Press

Harvard College Observatory

60 Garden Street

Cambridge, MA 02138
Mr John Rausch [2]

Division Head 06 Department

NAVOPINTCEN

4301 Suitland Road

Washington, DC 20390

Records Resource

The MITRE Corporation

Mailstop W115

7525 Colshire Drive

McLean, VA 22102

Dr Victor H Reis

US Department of Energy

DP-1, Room 4A019

1000 Independence Ave, SW.

Washington, DC 20585

Dr Fred E Saalfeld

Director

Office of Naval Research

800 North Quincy Street

Arlington, VA 22217-5000

Dr Dan Schuresko

O/DDS\&T

Washington, DC 20505

Dr John Schuster

Technical Director of Submarine and SSBN Security Program

Department of the Navy OP-02T

The Pentagon Room 4D534

Washington, DC 20350-2000

Dr Michael A Stroscio

US Army Research Office

P. O. Box 12211

Research Triangle NC 27709-2211 


\section{DISTRIBUTION LIST}

Superintendent

Code 1424

Attn Documents Librarian

Naval Postgraduate School

Monterey, CA 93943

Ambassador James Sweeney

Chief Science Advisor

USACDA

320 21st Street NW

Washington, DC 20451

Dr George W Ullrich [3]

Deputy Director

Defense Nuclear Agency

6801 Telegraph Road

Alexandria, VA 22310

Dr Walter N Warnick [25]

Deputy Director

Office of Planning \&Analysis, ER-5.1

Office of Energy Research

U S Department of Energy

Germantown, MD 2074

Dr Edward C Whitman

Dep Assistant Secretary of the Navy

C3I Electronic Warfare \& Space

Department of the Navy

The Pentagon 4D745

Washington, DC 20350-5000

Capt H. A. Williams, U S N

Director Undersea Warfare Space

\& Naval Warfare Sys Cmd

PD80

2451 Crystal Drive

Arlington, VA 22245-5200 